\title{
Male knowledge of birth preparedness in Ogun State, Nigeria: A rural/urban comparative cross-sectional study
}

\author{
Sodeinde $\mathrm{K}^{1}$, Bamidele $\mathrm{F}^{2}$, Adefala $\mathrm{N}^{2}$, Sodeinde $\mathrm{A}^{3}$ \\ ${ }^{1}$ Babcock University, Ilishan-Remo, Ogun State, Nigeria. \\ ${ }^{2}$ Babcock University Teaching Hospital, llishan-Remo, Ogun State, Nigeria. \\ ${ }^{3}$ Tai Solarin University of Education, ljagun, Ogun State, Nigeria.
}

\begin{abstract}
Objective: This study aimed to compare the knowledge of men concerning birth preparedness between rural and urban dwellers of Ogun State, Nigeria.

Methodology: This comparative cross-sectional study was conducted among 440 men each in rural and urban areas of Ogun State using a multistage sampling method to select participants. A structured intervieweradministered questionnaire was used to elicit data about respondents' socio-demographic characteristics and knowledge of birth preparedness. Knowledge was graded as good and poor knowledge. Data analysis was done with SPSS version 20 and presented as tables.

Results: The mean ages of the urban and rural respondents were $36.58 \pm 6.760$ and $37.61 \pm 9.788$ respectively. The difference in the mean age of urban and rural residents was not statistically significant $(t=-1.819, P=0.069)$. A higher proportion of urban respondents $(53.4 \%)$ had a statistically significant good knowledge of birth preparedness compared to $30.2 \%$ of rural men $(P<0.001)$. The association between age and knowledge of birth preparedness was statistically significant among rural respondents $(P<0.001)$ unlike urban respondents $(P=0.874)$. A statistically significant association was noted between education and knowledge $(P<0.001)$ in the urban area as against the rural area $(\mathrm{P}=0.084)$.

Conclusion: Knowledge of birth preparedness is better among male urban dwellers than their rural counterparts. Knowledge is statistically significantly associated with age in the rural area and with the level of education in the urban area. There is a need for an improved appropriate strategy that can raise knowledge of maternity care among rural men.
\end{abstract}

Keywords: Male, knowledge, Birth preparedness, rural/urban, Ogun State

\section{Background}

Despite the global reduction in maternal mortality recorded in the dawn of the new millennium, the world still failed to meet the Millennium Development Goals target of a $75 \%$ decline in the global Maternal Mortality Ratio (MMR) by 2015 (1). With the introduction of the Sustainable Development Goals, a decrease in maternal deaths continues to be of utmost importance with a global target of reducing MMR to fewer than 70 maternal deaths per 100,000 by the year 2030 (1). Moreover, no country is expected to have
MMR above 140 maternal deaths per 100,000 live births (1).

However, there has been an obvious persistence of disparities in maternal deaths among different climes. For instance, the sub-Saharan Africa region has the highest prevalence of MMR at 546 maternal deaths per 100,000 as against only 12 maternal deaths per 100,000 reported in developed countries (1). According to the National Demographic Health survey 2018, Nigeria has an MMR of 512 maternal deaths per 100,000 (2). Birth preparedness embraces the practice of preparation for uncomplicated births

Correspondence: Sodeinde Kolawole.

Department of Community Medicine,

Babcock University, Ilishan, Ogun State, Nigeria

+2348062957695; kolawolesodeinde024@gmail.com

(c) BUMJ. 2020 Open Access This article is distributed under the terms of the Creative Commons Attribution 4.0 International License

(http://creativecommons.org/licenses/by/4.0/), which permits unrestricted use, distribution, and reproduction in any medium, provided you give appropriate credit to the original author(s) and the source, provide a link to the Creative Commons license, and indicate if changes were made. The Creative Commons Public Domain Dedication waiver

(http://creativecommons.org/publicdomain/zero/1.0/) applies to the data made available in this article, unless otherwise stated. 
and forestalling the actions to be taken in the event of an emergency (3). It involves recognizing a skilled birth attendant, planning for means of transport, recognizing a health facility for delivery, saving money and identifying a potential blood donor in case the need arises for an obstetric emergency (3). The knowledge of men and their participation in birth preparedness is essential for women to patronize maternal health services and subsequently in reducing maternal morbidity and mortality (4). This is predominantly the case in male-controlled societies as seen in Nigeria and other African countries where men exercise enormous influence on the health of their spouses and offsprings (5). It has been documented that poor knowledge of birth preparedness is one of the reasons why men are not involved in maternal health care (6). For instance, the refusal of men to accompany their spouses to the hospital was ascribed to their ignorance of the importance of doing so during a Nigerian study (6). In a similar vein, men who were conversant with antenatal care (ANC) and who acquire knowledge from health workers were shown to be more likely to accompany their spouses to ANC in Tanzania (7).

As a component of antenatal care, couples should jointly be provided with comprehensive information about pregnancy and possible complications that may arise during childbirth (8). It has been documented that joint health talk with spouses is desired by most women so that the men can learn about optimum care for their pregnant wives (9). Unfortunately in developing countries, men are not allowed entrance into the clinics during health talk sessions (10). Despite, the importance of good male knowledge of birth preparedness in improving utilization of maternal health services and ensuring better health outcomes among women, their knowledge about maternity care has been documented to be poor particularly in developing countries (11).

Many factors have been postulated for the poor knowledge of birth preparedness among men in these areas. Since men seldom join their wives during health talk and clinical consultations, they become unacquainted with the preventive approaches that were deliberated at these periods. Consequently, men may not give adequate support to their wives, until perhaps complications arise (10). In some instances, it is the health workers who deliberately exclude men from getting the necessary information about maternal care (10). Other factors responsible for poor male knowledge include low facility delivery of pregnant women and insufficient public health awareness programs (12).

Strategies that can improve male participation in maternal health such as enhancing their knowledge of the subject should be given priority; bearing in mind the significant role of the man in ensuring positive maternal health outcomes (11). Moreover, evidence has shown that the knowledge of men about risky signs, birth preparedness and mitigation of complications during pregnancy are not sufficiently studied (7). Studies have shown rural-urban disparities in men's knowledge of birth preparedness and this may cause regional differences in utilization of maternal health care. For instance, men who dwelt in rural areas of southeastern Nigeria had a lower level of knowledge of birth preparedness as compared to their counterparts who were living in urban areas and place of residence was a significant predictor of men's knowledge of birth preparedness in this study (13). Similarly, men and their spouses who live in rural areas of Tanzania have lower knowledge of birth preparedness as compared to those who reside in urban residents (7).

\section{Methodology}

This study was conducted in Ogun State, Southwest Nigeria. The state has a projected population of 5,217,700 (14) people in 2016 who are mainly of the Yoruba tribe. Ogun state has many public and private health institutions that render maternal health services (15). The study design was community-based comparative cross-sectional conducted among 440 men each in the rural and urban areas of the state who were 18 years and above and whose spouses have had a minimum of one live birth in the last five years. Using a power of $80 \%$ and a confidence level of $95 \%$, the minimum required sample size was obtained from the formula for comparing proportions between two groups (16).

A multistage sampling method was adopted in selecting these participants. In stage one, simple random sampling was used to select one of the three senatorial districts in the state. Ogun Central senatorial district was selected. The senatorial district has six LGAs divided into five urban and one rural LGA. Odeda, the only rural LGA was included. Odeda LGA has a landmass of 1,560 square kilometres (17) with a projected population of 152,300 for the year 2016 (14). Simple random sampling was used to select one out of the five urban LGAs which turned out to be Abeokuta South LGA. The LGA has 15 wards, a projected population of 348,200 (14) in the year 
2016 and a total area of 71 square kilometres (18). In the next stage, simple random sampling was used to select five wards from each rural and urban LGA. Two settlements were selected from each ward making a total of ten settlements from each LGA. Eligible men in households in these settlements were interviewed.

The study instrument was a structured interviewer-administered questionnaire constructed from a review of literature on male contribution to Maternal Health Care $(6,19,20$, 21). and administered with the help of eight trained research assistants. The instrument was pre-tested in Lagos State which is in the same geo-political zone with the study area. The instrument assessed respondents' sociodemographic data and the knowledge of men concerning birth preparedness. Questions were asked if respondents knew about certain facts about birth preparedness. This included knowledge of the components of birth preparedness and knowledge of danger signs in pregnancy. The data were collected from October to December 2017.

Data were collated and analyzed using Statistical Package for Social Sciences (SPSS) version 20.0. Every correct knowledge answer was scored as 1 and wrong answers were scored as 0 . The mean knowledge score of respondents was calculated as 15.7 (approximated to 16). Average knowledge of at least 16 (mean score) was considered as good knowledge of birth preparedness and below 16 was considered as poor knowledge. Associations between categorical variables were tested with Chisquares, while the comparison between means was done with the student's t-test. The level of significance was set at a 95\% confidence interval with $P$ value $=0.05$. The analyzed data were presented as frequency tables. Ethical approval was obtained from the Health Research and Ethics Committee of the Olabisi Onabanjo University Teaching Hospital, Sagamu, Ogun State (OOUTH/HREC/64/2016). Verbal and written informed consent was obtained from the respondents and strict confidentiality of all information and results of findings were maintained throughout the study.

\section{Results}

Table 1 shows that the mean age of the urban respondent was $36.58 \pm 6.760$ while that of the rural respondents was $37.61 \pm 9.788$. The difference in the mean age of urban and rural residents was however not statistically significant $(\mathrm{t}=-1.819, \mathrm{P}=0.069)$. In the rural area, above onefifth $(21.1 \%)$ of the respondents had no formal education while only less than a tenth $(8.4 \%)$ of the urban participants had no formal education. The association between educational status and place of residence was statistically significant $(x 2=13.069, \quad P<0.001)$. The most common occupations in the rural and urban areas were farming (50.0\%) and civil service (28.6\%) respectively. The association between occupation and place of residence was also statistically significant $(\mathrm{X} 2=223.366, \mathrm{P}<0.001)$.

Table 1: Sociodemographic characteristics of respondents ( $\mathrm{N}=440$ per group)

\begin{tabular}{llll}
\hline Variable & Urban $\mathrm{n}(\%)$ & Rural $\mathrm{n}(\%)$ & Test Statistics \\
\hline Age Group (Years) & $7(1.6)$ & $11(2.5)$ & \\
$\leq 24$ & $172(39.1)$ & $178(40.5)$ & \\
$25-34$ & $205(46.6)$ & $152(34.5)$ & \\
$35-44$ & $53(12.0)$ & $69(15.7)$ & \\
$45-54$ & $3(0.7)$ & $30(6.8)$ & $\mathrm{X} 2=791.35, \mathrm{P}<0.001$ \\
$\geq 55$ & $36.58 \pm 6.760$ & $37.61 \pm 9.788$ & $\mathrm{t}=-1.819, \mathrm{P}=0.069$ \\
Mean & & & \\
Marital Status & $62(14.1)$ & $17(3.9)$ & \\
Single & $359(81.6)$ & $407(92.5)$ & \\
Married & $6(1.4)$ & $5(1.1)$ & $\mathrm{P} 2=29.775$ \\
Divorced & $13(2.9)$ & $11(2.5)$ & \\
Separated & & & \\
Highest Educational Status & & & \\
No Formal Education & $37(8.4)$ & 13001 & \\
Primary & $64(14.5)$ & $156(29.1)$ & $\mathrm{X} 2=13.069$ \\
Secondary & $127(28.9)$ & $61(13.9)$ & \\
Tertiary & $212(48.2)$ & & \\
Occupation & & $85(19.3)$ & \\
Trading & $115(26.1)$ & & \\
\hline
\end{tabular}




\begin{tabular}{llll}
\hline Farming & $29(6.6)$ & $220(50.0)$ & \\
Unskilled & $52(11.8)$ & $13(3.0)$ & \\
Semi-Skilled & $80(18.2)$ & $52(11.8)$ & \\
Professional & $29(6.6)$ & $5(1.1)$ & \\
Civil Servant & $126(28.6)$ & $57(13.0)$ & $\mathrm{X} 2=223.366$ \\
Unemployed & $9(2.0)$ & $8(1.8)$ & $\mathrm{P}<0.001$ \\
Religion & & & \\
Christianity & $268(60.9)$ & $258(58.6)$ & $\mathrm{X} 2=8.202$ \\
Islam & $169(38.4)$ & $167(38.0)$ & $\mathrm{P}=0.017$ \\
Traditional worshipper & $3(0.7)$ & $15(3.4)$ & \\
Ethnicity & $402(91.4)$ & $284(64.5)$ & \\
Yoruba & $28(6.4)$ & $30(6.8)$ & \\
Igbo & $4(0.9)$ & $103(23.4)$ & $\mathrm{X} 2=121.930$ \\
Hausa & $6(1.4)$ & $23(5.2)$ & $\mathrm{P}=<0.001$ \\
Others & & & \\
\hline
\end{tabular}

Table 2 shows the knowledge of birth preparedness among men. Arranging money for delivery is the most known preparation a man should make for childbirth. This knowledge is higher among rural respondents (84.5\%) compared to urban respondents (81.4\%). The difference in knowledge was, however, not statistically significant $(P=0.209)$. Knowledge of arranging for a skilled birth attendant was generally low among rural and urban respondents. However, this knowledge was higher among urban respondents (34.1\%) than rural respondents $(30.0 \%)$. The difference in knowledge was not statistically significant $(P=0.194 \%)$. Arranging for blood donors in the event of emergencies was the least known preparation a man should make for childbirth. The knowledge was however higher among urban respondents (15.5\%) than rural respondents (4.5\%). The difference in this knowledge was statistically significant $(\mathrm{P}<0.001)$.

Table 2: Knowledge of Components of Birth Preparedness ( $\mathrm{N}=440$ per group)

\begin{tabular}{|c|c|c|c|c|}
\hline Variable & Urban $\mathrm{n}(\%)$ & Rural n(\%) & $x^{2}$ & P-value \\
\hline \multicolumn{5}{|l|}{$\begin{array}{l}\text { A man's preparation for } \\
\text { childbirth include: }\end{array}$} \\
\hline Arrange money for delivery & $358(81.4)$ & $372(84.5)$ & 1.575 & 0.209 \\
\hline $\begin{array}{l}\text { Arrange a skilled birth } \\
\text { attendant }\end{array}$ & $150(34.1)$ & $132(30.0)$ & 1.691 & 0.194 \\
\hline Arrange for transportation & $308(70.0)$ & $205(46.6)$ & 49.588 & $<0.001$ \\
\hline Purchase birth kits & $309(70.2)$ & $171(38.9)$ & 87.285 & $<0.001$ \\
\hline Arrange blood donor & $68(15.5)$ & $20(4.5)$ & 29.091 & $<0.001$ \\
\hline $\begin{array}{l}\text { Decide the place of delivery } \\
\text { Heard about ANC before }\end{array}$ & $125(28.4)$ & $124(28.2)$ & 0.006 & 0.940 \\
\hline Yes & $431(98.0)$ & 422(95.9) & & \\
\hline No & $9(2.0)$ & $18(4.1)$ & 2.361 & 0.124 \\
\hline \multicolumn{5}{|l|}{$\begin{array}{l}\text { Place where women should } \\
\text { receive care during } \\
\text { pregnancy include }\end{array}$} \\
\hline It is not necessary & $45(10.2)$ & $6(1.4)$ & 31.658 & $<0.001$ \\
\hline Health facilities & 392(89.1) & $421(95.7)$ & 13.587 & $<0.001$ \\
\hline Traditional homes & $33(7.5)$ & $95(21.6)$ & 35.143 & $<0.001$ \\
\hline Mission homes & $48(10.9)$ & $120(27.3)$ & 38.138 & $<0.001$ \\
\hline $\begin{array}{l}\text { Chemist shops } \\
\text { A woman needs care and } \\
\text { support after delivery }\end{array}$ & $6(1.4)$ & $29(6.6)$ & 15.740 & $<0.001$ \\
\hline
\end{tabular}




\begin{tabular}{|c|c|c|c|c|}
\hline Yes & $420(95.5)$ & 436(99.1) & & \\
\hline No & $20(4.5))$ & $4(0.9)$ & 15.410 & $<0.001$ \\
\hline
\end{tabular}

Only responses in the affirmative were reported

Table 3 shows vaginal bleeding $(78.9 \%$ urban; $69.8 \%$ rural) was the most known danger sign in pregnancy and that this knowledge was significantly higher among urban respondents $(P=0.002)$. This was followed by swollen legs and face (56.1\% urban and $57.7 \%$ rural). Only a few of the respondents knew that blurred vision was a sign of danger in pregnancy and that proportion of respondents who knew this was significantly higher in the urban area $(P=0.019)$. A significantly higher proportion of respondents in the urban area also knew the loss of consciousness (urban 45.7; rural 18.0; $\mathrm{P}<0.001$ ) as danger signs in pregnancy as compared to their rural counterparts. During labour and delivery, retained placenta $(81.8 \%)$, severe vaginal bleeding $(72.0 \%)$ and prolonged labour $(68.0 \%)$ were the three most known danger signs in the urban area while severe vaginal bleeding $(60.5 \%)$, retained placenta $(58.6 \%)$, and convulsion $(29.1 \%)$ were the three most known danger signs in the rural area. The difference in knowledge of severe vaginal bleeding $(\mathrm{P}<0.001)$, Prolonged labour $(\mathrm{P}<0.001)$, Convulsion $(P<0.001)$, Retained placenta $(P<0.001)$ and loss of consciousness $(P<0.003)$ as danger signs in labour were all statistically significantly higher in urban areas compared to rural areas.

Table 3: knowledge of danger signs in pregnancy and labour ( $\mathrm{N}=440$ per group)

\begin{tabular}{lllll}
\hline Variable & Urban $\mathrm{n}(\%)$ & Rural $\mathrm{n}(\%)$ & $\mathrm{X}$ & P-Value \\
\hline Danger signs in & & & & \\
Pregnancy included & & & & \\
Vaginal bleeding & $347(78.9)$ & $307(69.8)$ & 9.526 & 0.002 \\
Severe headache & $127(28.9)$ & $138(31.4)$ & 0.653 & 0.419 \\
Blurred vision & $95(21.6)$ & $68(15.5)$ & 5.489 & 0.019 \\
General body weakness & $140(31.8)$ & $181(41.1)$ & 8.244 & 0.004 \\
Swollen leg and face & $247(56.1)$ & $254(57.7)$ & 0.227 & $<0.001$ \\
Loss of consciousness & $201(45.7)$ & $79(18.0)$ & 77.964 & $<0.001$ \\
High Fever & $116(26.4)$ & $63(14.3)$ & 19.700 & \\
Danger signs in & & & & $<0.001$ \\
labour/Delivery include & & & & $<0.001$ \\
Severe vaginal bleeding & $317(72.0)$ & $266(60.5)$ & 13.219 & $<0.001$ \\
Prolonged labour> 12 hours & $299(68.0)$ & $109(24.8)$ & 164.963 & 0.001 \\
Convulsion & $181(41.1)$ & $128(29.1)$ & 14.010 & 0.133 \\
Retained placenta & $360(81.8)$ & $258(58.6)$ & 56.545 & 0.003 \\
High fever & $99(22.5)$ & $81(18.4)$ & 2.263 & \\
Loss of consciousness & $143(32.5)$ & $104(23.6)$ & 8.561 & \\
\hline
\end{tabular}

Only responses in the affirmative were reported

Table 4 shows that a higher proportion of urban respondents $(53.4 \%)$ had statistically significant overall good knowledge of birth preparedness compared to $30.2 \%$ of rural men $(\mathrm{P}<0.001)$.

Table 4: Knowledge Score of birth preparedness ( $\mathrm{N}=440$ per group)

\begin{tabular}{llll}
\hline Variable & Urban $\mathrm{n}(\%)$ & Rural $\mathrm{n}(\%)$ & $\mathrm{X}$ \\
\hline Poor Knowledge & $205(46.6)$ & $307(69.8)$ & $\mathrm{X} 2=48.592$ \\
Good Knowledge & $235(53.4)$ & $133(30.2)$ & $\mathrm{P}<0.001$ \\
Total & $440(100.0)$ & $440(100.0)$ & \\
Mean & $17.02 \pm 5.129$ & $14.39 \pm 4.779$ & \\
\hline
\end{tabular}

Mean $15.70 \pm 5.126$

Table 5 shows that the association between age and knowledge of birth preparedness was statistically significant among rural respondents
$(\mathrm{P}<0.001)$ but not statistically significant among urban respondents $(P=0.874)$. Participants' occupations were also significantly associated 
with knowledge of birth preparedness in urban $(P=0.017)$ and rural areas $(P<0.001)$. Statistically significant associations were also noted between marital status $(P=0.003)$ and education $(P<0.001)$ with knowledge in the urban area whereas these associations were not statistically significant in the rural area ( $P=0.736$ and 0.084 respectively).

Table 5: Knowledge of birth preparedness by socio-demographic characteristics of respondents in urban and rural communities ( $\mathrm{N}=440$ per group)

\begin{tabular}{|c|c|c|c|c|}
\hline Variable & \begin{tabular}{l}
\multicolumn{1}{c}{ Urban } \\
Poor Knowledge \\
$\mathrm{N}(\%)$
\end{tabular} & $\begin{array}{l}\text { Good Knowledge } \\
\mathrm{n}(\%)\end{array}$ & \begin{tabular}{l}
\multicolumn{1}{c}{ Rural } \\
Poor Knowledge \\
N (\%)
\end{tabular} & $\begin{array}{l}\text { Good Knowledge } \\
\mathrm{n}(\%)\end{array}$ \\
\hline \multicolumn{5}{|l|}{ Age Group(Years) } \\
\hline$\leq 24$ & $3(42.9)$ & $4(57.1)$ & 11(100.0) & $0(0.0)$ \\
\hline $25-34$ & $79(45.9)$ & $93(54.1)$ & $126(70.8)$ & $52(29.2)$ \\
\hline $35-44$ & $100(48.8)$ & $105(51.2)$ & $117(77.0)$ & $35(23.0)$ \\
\hline $45-54$ & $22(41.5)$ & $31(58.5)$ & $33(47.8)$ & $36(52.2)$ \\
\hline$\geq 55$ & $1(33.3)$ & $2(66.7)$ & $20(66.7)$ & $10(33.3)$ \\
\hline X2(P Value $)$ & $1.226(0.874)$ & & $24.485(<0.001)$ & \\
\hline \multicolumn{5}{|l|}{ Marital Status } \\
\hline Single & $42(67.7)$ & $20(32.3)$ & $10(58.8)$ & $7(41.2)$ \\
\hline Married & $156(43.5)$ & $203(56.5)$ & $285(70.0)$ & $122(30.0)$ \\
\hline Divorced & $3(50.0)$ & $3(50.0)$ & $4(80.0)$ & $1(20.0)$ \\
\hline Separated & $4(30.8)$ & $9(69.2)$ & $8(72.7)$ & $3(27.3)$ \\
\hline $\begin{array}{l}\text { X2(P Value) } \\
\text { Educational Status }\end{array}$ & \multicolumn{3}{|c|}{ Éducational Status } & \\
\hline No Formal Education & $27(73.0)$ & $10(27.0)$ & $74(79.6)$ & 19(20.4) \\
\hline Primary & $42(65.6)$ & $22(34.4)$ & $90(69.2)$ & $40(30.8)$ \\
\hline Secondary & $57(44.9)$ & $70(55.1)$ & $100(64.1)$ & $56(35.9)$ \\
\hline Tertiary & $79(37.3)$ & $133(62.7)$ & $43(70.5)$ & $18(29.5)$ \\
\hline $\begin{array}{l}\text { X2(P Value }) \\
\text { Occupation }\end{array}$ & $27.227(<0.001)$ & & $6.644(0.084)$ & \\
\hline Trading & $58(50.4)$ & $57(49.6)$ & $59(69.4)$ & $26(30.6)$ \\
\hline Agricultural Worker & $12(41.4)$ & $17(58.6)$ & $167(75.9)$ & $53(24.1)$ \\
\hline Unskilled & $35(67.3)$ & $17(32.7)$ & $2(15.4)$ & $11(84.6)$ \\
\hline Semi-skilled & $38(47.5)$ & $42(52.5)$ & $33(63.5)$ & $19(36.5)$ \\
\hline Professional & $12(41.4)$ & $17(58.6)$ & $2(40.0)$ & $3(60.0)$ \\
\hline Civil Servant & $46(36.5)$ & $80(63.5)$ & $38(66.7)$ & $19(33.3)$ \\
\hline Unemployed & $4(44.4)$ & $5(55.6)$ & $6(75.0)$ & $2(25.0)$ \\
\hline X2(P Value $)$ & $15.476(0.017)$ & & $25.614(<0.001)$ & \\
\hline \multicolumn{5}{|l|}{ Ethnicity } \\
\hline Yoruba & $187(46.5)$ & $215(53.5)$ & $193(68.0)$ & $91(32.0)$ \\
\hline Igbo & $12(42.9)$ & $16(57.1)$ & $18(60.0)$ & $12(40.0)$ \\
\hline Hausa & $3(75.0)$ & $1(25.0)$ & $78(75.7)$ & $25(24.3)$ \\
\hline Others & $3(50.0)$ & $3(50.0)$ & $18(78.3)$ & $5(21.7)$ \\
\hline X2(P Value) & $1.483(0.686)$ & & $4.320(0.229)$ & \\
\hline
\end{tabular}

\section{Discussion}

Birth preparedness is a vital tactic that ensures women have prompt access to skilled care during pregnancy and childbirth (22). This safeguards against undesirable health outcomes for women and newborns (22). What men know concerning birth preparedness has substantial influence in their participation in maternity care in a positive direction $(12,23)$, and subsequently in the utilization of maternal health services (23).
Like many developing countries $(7,19,24)$ male knowledge of maternity care in this current study is poor. This may be relatively due to the erroneous belief that childbirth is exclusively the woman's responsibility in these areas (6). Therefore, the men do not bother to acquire knowledge about pregnancy and childbirth. The implication of this may be reduced utilization of maternal health services since men are regarded as decision-makers concerning the health of their 
family especially in patriarchal societies like this study area.

Furthermore, this current study reveals knowledge of birth preparedness was significantly better among urban participants as compared to rural participants where knowledge was particularly low. This may be because more urban residents had formal education which has been linked with improved male knowledge of family and reproductive health (20). It may also be because urban dwellers have more access to information through academic and health institutions, mass and social media which are more available and accessible in the urban areas. This particularly low level of knowledge in the rural area was also reported in Tanzania (7). However, the finding is in contrast to what was reported in rural Kenya where men had good knowledge (5).

In this current study, arranging money for delivery was the most known preparation a man should make for childbirth with a slightly higher proportion of rural residents knowing this and therefore, the difference in this knowledge was not statistically significant. This similar pattern of knowledge was documented in Ethiopia (20). Men are more concerned about financial responsibility than other aspects of birth preparedness $(6,25)$. In another similar study also in Southwest Nigeria, many of the men knew financial commitment as their only role in ANC (19). Increase knowledge of providing money for maternity care may be because men are usually the breadwinner in many developing countries whose responsibility is particularly to provide financial support for the wife and children. The implication of this may be that men may be nonchalant about other components of birth preparedness and complication readiness.

The World Health Organization (WHO) defines a skilled birth attendant (SBA) as an accredited health professional such as a midwife, doctor or nurse who has been educated and trained to proficiency in the skills needed to manage normal (uncomplicated) pregnancies, childbirth and the immediate postnatal period, and in the identification, management and referral of complications in women and newborns (26). The organization, therefore, advocates the presence of SBA at every delivery because their presence during delivery is crucial in reducing maternal and child deaths (26).

Men influence the utilization of health facilities and SBAs by their wives (27). In this current study, only a few men in both urban and rural areas knew they were to arrange for skilled birth attendants for their pregnant wives. Since male knowledge of birth preparedness is a determinant of their involvement (6) which in turn enhances the utilization of health services by women, poor men knowledge of SBAs may lead to deliveries unsupervised by these professionals, hence increased risk of maternal morbidity and mortality (26). This finding is similar to what was reported in Ethiopia where only $32.7 \%$ of men knew they had to arrange for a skilled birth attendant (20). It, however, differs from the report of a similar study in Southwest Nigeria where most of the men knew they were to arrange for a skilled attendant for their pregnant wives (19). The higher proportion of urban men who knew about preparation for a skilled birth attendant in this current study is not surprising since it has been reported that the urban area of Nigeria has a higher proportion of SBA-supervised deliveries as compared to the rural areas (27).

Increased spousal knowledge of danger signs during pregnancy and labour somewhat contributes to a reduction in maternal mortality (24). This is partly because improved knowledge of obstetric complications is key in prompt utilization of health services (28). In this current study, vaginal bleeding and swollen leg and face were the most frequently known danger signs in pregnancy by participants in both urban and rural areas. During labour and delivery, the most frequently known danger signs were severe vaginal bleeding and retained placenta with statistically significantly higher knowledge among participants in the urban area as compared to their counterparts in the rural area. This might be attributed to the fact that these signs are directly linked with pregnancy and labour and are therefore easily recognizable by pregnant women, their spouses, and neighbours. On the other hand, only a small proportion of respondents in both urban and rural areas identified blurred vision and severe headache as danger signs during pregnancy. Likewise, few of the men recognized convulsion and loss of consciousness as danger signs in labour. This may be because these signs are not directly related to obstetric factors and that the signs have multiple causes. Since men are decision-makers in the family including areas of health-seeking behaviour, poor identification of danger signs may have unpleasant consequences.

The pattern of recognizable danger signs in this study is a little different from what was documented in Edo State (21), South-south Nigeria where the three most frequently recognized danger signs in pregnancy were 
vaginal bleeding (100.0\%), convulsion (96.2\%) and blurred vision (95.8\%). In labour, the most frequently recognized symptoms were severe vaginal bleeding $(100.0 \%)$, convulsion $(99.6 \%)$ and high fever (92.4\%). The findings in this current study also differs a little from what was found in Northern Nigeria where vaginal bleeding $(51.9 \%)$, convulsion (37.8\%) and loss of consciousness $(33.2 \%)$ were the most frequently known danger signs in pregnancy (6).

Men's socio-demographic characteristics influence their knowledge and involvement in birth preparedness. A study in Northern Nigeria reported age, educational status, and ethnicity as predictors of male involvement in maternity care. In Rwanda (29) and Malawi (30), education and age have been shown to determine male knowledge in Maternity care. In this current study, age is significantly associated with male knowledge in rural areas but not in urban areas. On the other hand, marital status and level of education are significantly associated with male knowledge in the urban area but not in the rural area. However, there is no significant relationship between ethnicity and male knowledge in both urban and rural areas. This may be a result of the presence of various ethnic groups in both urban and rural areas of the state.

The implication of the findings of this study particularly in rural areas where men's knowledge of birth preparedness is poor is policy and program in the context of improving male interest, knowledge, and participation in maternal health care. The cross-sectional nature of this study and the absence of multivariate analysis poses a limitation to the study as factors associated with male knowledge of birth preparedness cannot be specified.

\section{Conclusion}

Male knowledge of birth preparedness was better among urban dwellers compared to their rural counterparts. There is a need for improved strategy in the context of raising men's awareness about maternity care.

\section{List of Abbreviations}

ANC: Antenatal Care

LGA: Local Government Area

MMR: Maternal Mortality Ratio

SBA: Skilled Birth Attendant

SPSS: Statistical Package for Social Sciences

WHO World Health Organization

\section{Declarations}

Ethics approval and consent to participate Ethical approval was obtained from the Health Research and Ethics Committee of the Olabisi Onabanjo University Teaching Hospital, Sagamu, Ogun State (OOUTH/HREC/64/2016). Verbal and written informed consent was obtained from the respondents and strict confidentiality of all information and results of findings were maintained throughout the study.

\section{Consent for Publication}

The authors hereby transfer all copyright ownership exclusively to the journal, if this work is published by the journal.

\section{Conflicts of Interest}

The authors have declared no conflict of interest.

\section{Funding}

The authors received no research funding.

\section{Authors Contributions}

JS conceived the research idea and wrote the first draft. All authors drafted, reviewed the manuscript and approved the final submission.

\section{References}

1. Maternal Health Task Force. The Sustainable Development Goals and Maternal Mortality. Available at https://www.mhtf.org/topics/thesustainable-development-goals-andmaternal-mortality/ Accessed on 6/03/2020.

2. National Population Commission. ICF International: Nigeria Demographic and Health Survey 2018. Abuja, Nigeria. 2019. Available

at https://dhsprogram.com/pubs/pdf/SR264/SR 264.pdf. Accessed on 6/03/2020.

3. The world health report 2005: make every mother and child count Policy brief one: integrating maternal, newborn and child health programmes. Geneva: World Health Organization; 2005 Available at https://www.who.int/whr/2005/media centre/ pb 1 en.pdf. Accessed on 7/03/2020

4. Bhusai CK, Bhattarai S. Involvement of male in birth preparedness in Tulsipor Municipality of Dang District, Nepal. Journal of Chitwan Medical College. 2017; 5(14):33-38. https://doi.org/10.3126/jcmc.v5i4.16550

5. Dunn A, Haque S, Innes M. Rural Kenyan men's awareness of danger signs of obstetric complications. Pan Afr Med J 2011; 10:39 
6. Illiyasu Z, Abubakar IS, Galadanci HS. Aliyu $\mathrm{MH}$. Birth preparedness, complication readiness and fathers' participation in maternity care in a northern Nigerian community. Afr J Reprod Health, 2010; 14(1):21-32.

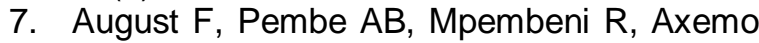
$P$ and Darj E. Men's Knowledge of Obstetric Danger Signs, Birth Preparedness and Complication Readiness in Rural Tanzania. PLoS One. 2015; 10(5): e0125978. https://doi.org/10.1371/journal.pone.012597 $\underline{8}$

8. Carroli G, Villar J, Piaggio G, Khan-Neelofur $D$, Gülmezoglu M, Mugford $M$ et al. WHO systematic review of randomised controlled trials of routine antenatal care. The Lancet. 2001;357(9268):1565-1570.

https://doi.org/10.1016/s0140-

6736(00)04723-1

9. Adeniran AS, Aboyeji AP, Fawole AA, Balogun RO, Adesina KT, Adeniran PI. Male partner's role during pregnancy, labour, and delivery: expectation of pregnant women in Nigeria. Int J Health Sci (Qassim) 2015; 9(3):305-313. https://doi.org/10.12816/0024697

10. Mullick S, Kunene B, and Wanjiru M. Involving men in maternity care: health service delivery issues. Agenda Special Focus 2005; 6: 124-35. Available at http://citeseerx.ist.psu.edu/viewdoc/downloa $\mathrm{d}$ ?doi=10.1.1.192.5507\&rep=rep1\&type=pdf.

11. Mersha, A.G. Male involvement in the maternal health care system: implication towards decreasing the high burden of maternal mortality. BMC Pregnancy and Childbirth 2018; 18(1): 493. https://doi.org/10.1186/s12884-018-2139-9

12. Gize, A., Eyassu, A., Nigatu, B. et al. Men's knowledge and involvement on obstetric danger signs, birth preparedness and complication readiness in Burayu town, Oromia region, Ethiopia. BMC Pregnancy and Childbirth 2019; 515. https://doi.org/10.1186/s12884-019-2661-4

13. Ekabua JE, Ekabua KJ, Odusolu P, Thomas UA, Iklaki CU, Etokidem AJ. Awareness of birth preparedness and complication readiness in south eastern Nigeria. ISRN Obstetrics and Gynaecology 2011, Article ID 560641, 6 pages. https://doi.org/10.5402/2011/560641

14. Ogun State, Nigeria. Population Statistics Charts, Map and Location. Available at https://citypopulation.de/php/nigeriaadmin.php. Accessed on 12/04/2020.

15. Ogun State Ministry of Health. Ogun State Health Bulletin 2010. Available at https://mamaye.org.ng. Accessed on 04/10/15.

16. Taylor DW. The calculation of sample size and power in the planning of experiments. Dept. Clin. Epid. Biostat. McMaster University. Hamilton Ontario, Canada. 1994:1-23.

17. Odeda-Ogun Statebiz. Available at https://ogunstatebiz.tripod.com. Accessed on 11/08/17.

18. Abeokuta South- Ogun Statebiz. Available at https://ogunstatebiz.tripod.com. Accessed on 11/08/17.

19. Olugbenga-Bello $A$, Asekun-Olarinmoye EO, Adewole AO, Adeomi AA, Olanrewaju SO. Perception, attitude, and involvement of men in maternity health care in a Nigerian Community. J Pub Health Epidemiology. 2013; 5(6): 262-70.

20. Gebrehiwot H, Gebregziabher W, Gidey Gebreamiak. Assessment of husbands' participation in birth preparedness and complication readiness in Enderta Woreda, Tigray Region, Ethiopia, 2012. J Women's Health Care 2013; 3:140. https://doi.org/10.4172/2167-0420.1000140

21. Obi Al, Abe E, Okojie OH. Male and community involvement in birth preparedness and complication readiness in Benin City, Southern Nigeria. IOSR Journal of Dental and Medical Sciences 2013; 10(6): 27-32. https://doi.org/10.9790/0853-1062732

22. Nanjala M, Walmawa D. Determinants of male partner involvement in promoting deliveries by skilled attendants in Busia, Kenya. Glob J Health Sci 2012; 4:60-7. https://dx.doi.org/10.5539\%2Fgjhs.v4n2p60

23. Othman K, Dan KK, Michael OO. Male involvement in birth preparedness and complication readiness for emergency obstetric referrals in rural Uganda. Reprod Health 2011; 8:12. https://doi.org/10.1186/1742-4755-8-12

24. Tamiso A, Merdekios $B$, Tilahum $M$. Association of men's awareness of danger signs of obstetric complication and male involvement in birth preparedness practices at South Ethiopia. International Journal of Public Health Science 2015; 4(1):63-70. https://doi.org/10.11591/ijphs.v4i1.4713

25. Dumbaugh $M$, Tawiah-Agyemang $C$, Manu A, Ha ten Asbroek G, KirkwundM, Hill Z. 
Perception of, attitude towards and barriers to male involvement in newborn care in rural Ghana, West Africa: a qualitative analysis. BMC Pregnancy and childbirth 2014; 14:269. https://doi.org/10.1186/1471-2393-14-269

26. WHO. Skilled birth attendant Situation and trends. Available at https://www.who.int/gho/maternal health/skil led care/skilled birth attendance text/en/ Accessed on 18/03/2020.

27. National Population Commission. ICF International: Nigeria Demographic and Health Survey 2013. Abuja, Nigeria. 2014. Available at https://www.dhsprogram.com/pubs/pdf/FR29 3/FR293.pdf. Accessed on 12/04/2020.

28. Lori JR, Dahlem C.H, Aekah JV, Adanu RMK: Examining antenatal health literacy in Ghana.
J Nursing Scholarship, 2014; 46(6): 432-40. https://doi.org/10.1111/inu.12094

29. Kowalczyk J, Jolly P, Karita E, Nibarere JA, Vyankandondera J, Salihu H. Voluntary Counselling and Testing for HIV among pregnant women presenting in labour in Kigali, Rwanda. J Acquir Immune Def Syndr. 2002;31(4):408-415.

https://doi.org/10.1097/00126334200212010-00007

30. Lucy IK, Johanne S, Address M, Ellen C. Striving to promote male involvement in maternal health care in rural and urban settings in Malawi- a qualitative study. Reprod Health 2011; 8:36. https://doi.org/10.1186/1742-4755-8-36 